$\$=$

\title{
Utilization of clinical practice guidelines: a survey of Canadian pediatric physicians
}

\author{
Fareeha Nasir ${ }^{1}$, Katharine Nicholson ${ }^{2}$, Ben Vandermeer ${ }^{1}$, Manoj Kumar ${ }^{1}$, Joan L. Robinson ${ }^{1 *}$ \\ ${ }^{I}$ Stollery Children's Hospital and University of Alberta, Edmonton, Alberta \\ ${ }^{2}$ Children's Hospital of Eastern Ontario and University of Ottawa, Ottawa, Ontario \\ *Corresponding author E-mail: jr3@ ualberta.ca
}

\begin{abstract}
Background: It is not clear how physicians currently use clinical practice guidelines (CPGs).

Objectives: The objective was to describe how Canadian pediatric residents and pediatricians use CPGs and to identify barriers to CPG use.

Methods: Pediatric emergency physicians and general pediatricians in Edmonton and Ottawa and all Canadian pediatric residents were surveyed regarding patterns of use for CPGs and barriers to use.

Results: Response rate was $178 / 847(21 \%)$. The majority of responding residents $(62 \%)$, emergency physicians (54\%) and general pediatricians teaching more than 6 weeks annually on a clinical teaching unit (CTU) use CPGs at least monthly (55\%) with less frequent use by pediatricians who teach 1 to 6 weeks on CTU $(14 \%)$ or rarely/never teach on CTU $(21 \%)(\mathrm{p}<0.001)$. Canadian physicians are more likely to read Canadian Paediatric Society guidelines when they are published versus referring to them later when dealing with clinical problems while the opposite appears to be true for American Academy of Pediatrics guidelines. The most common barrier to use of guidelines is forgetting that a guideline exists for a specific problem. The majority of physicians access CPGs electronically and support development of web based tools to improve accessibility.

Conclusions: Almost all pediatric residents, pediatric emergency physicians and general pediatricians sometimes refer to CPGs. General pediatricians teaching less than 6 weeks per year on CTUs are an important target population, as most use CPGs infrequently. Prompts that CPGs exist and accessible online summaries of CPGs appear to have potential for overcoming the barriers to use.
\end{abstract}

Keywords: Clinical Practice Guidelines; Continuing Medical Education; Cross-Sectional Studies; Pediatrics; Survey.

\section{Introduction}

Clinical practice guidelines (CPGs) are designed to incorporate evidence based medicine into clinical practice. They are also used as targets for quality assurance, as teaching resources, and as practice standards for medical liability cases (Flores et al. 2000). Following CPGs can improve patient outcomes (Han et al. 2003), optimize antimicrobial stewardship (Newman et al. 2012), promote cost effective management strategies (Crabtree et al. 2011), and potentially foster equity in medical care (Cabana et al. 2011). However, acceptance of guidelines (Flores et al. 2000) and adherence to guidelines (Meehan et al. 2010) are limited.

Undoubtedly, much expense and effort is devoted to producing and updating CPGs but little research has explored how they are being utilized. American Academy of Pediatrics (AAP) members were surveyed 14 years ago (Flores et al. 2000). While $82 \%$ were familiar with CPGs, only $35 \%$ reported using entire CPGs in their practice while another $44 \%$ reported using parts of CPGs. Just 3\% believed that CPGs represented the standard of care. The respondents identified the lack of autonomy and dislike of "cook-book" medicine as the biggest barriers to use. The overwhelming majority preferred print-based over web-based CPGs.

CPGs and the internet have flourished in the intervening 14 years and attitudes may have changed. The aim of this study was to describe attitudes towards and use of CPGs by pediatric physi- cians, hoping that this could lead to recommendations for ways to improve uptake of CPGs. The specific objectives were to determine which sources pediatric physicians in Canada most commonly used for clinical advice, how often these sources are Canadian Paediatric Society (CPS) or AAP CPGs, patterns of reviewing and utilizing CPS and AAP CPGs, level of agreement with CPGs, barriers to use of CPGs and opinions about how to make CPGs more useful.

\section{Methods}

This study was approved by both the University of Alberta and the Children's Hospital of Eastern Ontario Research Ethics Boards. The participation of pediatric residents was approved by the $\mathrm{Ca}$ nadian Paediatric Program Directors.

\subsection{Study design and population}

This was a cross-sectional survey of all residents in Canadian general pediatric programs and of general pediatricians and emergency room physicians affiliated with the Stollery Children's Hospital in Edmonton, Alberta and the Children's Hospital of Eastern Ontario in Ottawa, Ontario. The small number of pediatricians in these cities not affiliated with these hospitals could not be surveyed as there is no publically available contact list. Fulltime and part-time emergency room physicians were eligible if 
they had completed specialty training in pediatrics or worked almost full-time in a pediatric emergency department. Pediatricians who were no longer in practice were excluded.

\subsection{Measurement tool}

A questionnaire was designed using recommended methods (Burns et al. 2008) (Appendix A). The questionnaire was piloted by four pediatric residents, one emergency physician and three general pediatricians in Edmonton for clarity and content, resulting in minor changes in format and wording.

\subsection{Procedures}

Data were collected and managed using REDCap (Research Electronic Data Capture) (Harris et al. 2009). Links to the web-based questionnaire and two reminders were distributed by email to all general pediatric residents in Canada by REDCap in June 2013, using email addresses provided through the Canadian Paediatric Program Directors.

Emergency room physicians and general pediatricians were identified using lists maintained by the pediatric departments. Those with email addresses were sent a link to a web-based questionnaire with two email reminders. Those without email addresses were mailed a paper based copy of the questionnaire to complete without reminders; a self-addressed stamped envelope was provided.

All responses were anonymous. Consent was implied by the participants' decision to complete the questionnaire.

\subsection{Data analysis}

In addition to residents, pediatricians were divided into four groups based on their pattern of practice: 1) pediatric emergency room physicians (EP) 2) general pediatricians who usually teach more than 6 weeks per year on a clinical teaching unit (GPA) 3 ) general pediatricians who work an average of one to six weeks per year on a clinical teaching unit (GPB) and 4) general pediatricians working in the community who rarely or never work on a clinical teaching unit (GPC).

Patterns of use for CPGs were compared for residents, EP, GPA, GPB and GPC and for males versus females. For pediatricians, a correlation between age and years of experience and use of CPGs was sought. Dichotomous data was compared using the binomial test (single group comparison), Fisher's exact test (two group comparison) or the Fisher-Freeman-Halton test (three or more groups). Ordinal data was analyzed using the Kruskal Wallis test (two groups). Continuous data was examined using a paired t-test (two groups) or one way ANOVA (three or more groups).

The primary outcome was the proportion of guideline users in each group. The sample size cannot be controlled for a survey. However, prior to the study, we determined that with minimum 10 responses from each of the 5 groups, we would be able to detect an effect size of 0.55 in the primary outcome of proportion of guideline users between the five groups using a 8 degrees of freedom Chi-Square Test with $80 \%$ power at a $5 \%$ significance level (Type-I error rate). The actual sample size was 177 respondents, allowing detection of an effect size of 0.29 .

\section{Results}

All 636 general pediatric residents in Canada were sent the webbased questionnaire via email. In addition, 211 pediatricians (95 from Ottawa and 116 from Edmonton) were asked to complete the questionnaire (197 by email, 14 by paper).

There were 177 responses from 54 males and 123 females. In total 88 pediatric residents (12 in year one, 27 in year two, 25 in year three and 24 in year four of training) started the questionnaire for a response rate of $14 \%$, but 8 submitted incomplete questionnaires. One pediatrician who started the questionnaire was excluded as they were no longer in practice. In addition, $38 \mathrm{EP}, 11 \mathrm{GPA}, 15$ GPB and 25 GPC started the questionnaire for a response rate of $42 \%$ with 2 submitting incomplete questionnaires.

\subsection{Sources for clinical advice}

For clinical advice, the online database UpToDate was used at least once per week by $71 \%$ of residents and $51 \%$ of staff pediatricians, making this reference the most popular (Table 1).

Table 1: Frequency of Referring to Resources for Clinical Advice as Reported by Residents, Emergency Physicians and General Pediatrician's Total Number of Respondents (\% of Group).

\begin{tabular}{|c|c|c|c|}
\hline Resource & Frequency & $\begin{array}{l}\text { Pediatricians EP, } \\
\text { GPA, GPB, GPC } \\
(n=86)\end{array}$ & $\begin{array}{l}\text { Residents } \\
\text { Years 1-4 } \\
(n=80)\end{array}$ \\
\hline \multirow{3}{*}{ UpToDate } & $\begin{array}{l}\text { At least } \\
\text { once/week }\end{array}$ & $44(51 \%)$ & $57(71 \%)$ \\
\hline & $\begin{array}{l}\text { Less than } \\
\text { once/week }\end{array}$ & $22(26 \%)$ & $21(26 \%)$ \\
\hline & Never & $20(23 \%)$ & $2(3 \%)$ \\
\hline \multirow{3}{*}{ Medline/Pubmed } & $\begin{array}{l}\text { At least } \\
\text { once/week }\end{array}$ & $30(35 \%)$ & $26(33 \%)$ \\
\hline & $\begin{array}{l}\text { Less than } \\
\text { once/week }\end{array}$ & $46(54 \%)$ & $47(59 \%)$ \\
\hline & Never & $9(11 \%)$ & $7(9 \%)$ \\
\hline \multirow{3}{*}{ Textbook } & $\begin{array}{l}\text { At least } \\
\text { once/week }\end{array}$ & $12(14 \%)$ & $22(28 \%)$ \\
\hline & $\begin{array}{l}\text { Less than } \\
\text { once/week }\end{array}$ & $62(72 \%)$ & $47(59 \%)$ \\
\hline & Never & $12(14 \%)$ & $11(14 \%)$ \\
\hline \multirow{3}{*}{ CPS CPGs } & $\begin{array}{l}\text { At least } \\
\text { once/week }\end{array}$ & $21(24 \%)$ & $22(28 \%)$ \\
\hline & $\begin{array}{l}\text { Less than } \\
\text { once/week }\end{array}$ & $58(67 \%)$ & $58(73 \%)$ \\
\hline & Never & $7(8 \%)$ & $0(0 \%)$ \\
\hline \multirow{3}{*}{ AAP CPGs } & $\begin{array}{l}\text { At least } \\
\text { once/week }\end{array}$ & $11(13 \%)$ & $3(4 \%)$ \\
\hline & $\begin{array}{l}\text { Less than } \\
\text { once/week }\end{array}$ & $61(71 \%)$ & $72(90 \%)$ \\
\hline & Never & $14(16 \%)$ & $5(6 \%)$ \\
\hline
\end{tabular}

Legend: AAP: American Academy of Pediatrics; CPG: clinical practice guideline; CPS: Canadian Paediatric Society; EP: Emergency physicians; GPA: General pediatricians who work $>6$ weeks/year on a clinical teaching unit (CTU); GPB: General pediatricians who work 1-6 weeks/year on CTU; GPC: General pediatricians who rarely or never work on CTU.

Medline/Pubmed, textbooks, and CPGs published by the CPS and AAP were consulted at a lower frequency by all users. Other resources mentioned by respondents included published review articles, hospital based guidelines, provincial guidelines, CPGs published by sub-specialty organizations (e.g. Canadian Diabetes Association, Canadian ADHD Resource Alliance, American Academy of Neurology) and international CPGs.

\subsection{Patterns of reviewing and utilizing CPGs}

The majority of responding residents $(62 \%)$ use CPGs to manage specific cases more than once per month and only $2 \%$ claim to never refer to CPGs (Figure 1).

There was no significant difference between reported CPG use in junior (year 1 and 2 of training) versus senior (year 3 and 4 of training) residents $(\mathrm{p}=0.12)$. Emergency physicians $(\mathrm{EP})$ showed a variable pattern of clinical practice CPG usage: $54 \%$ use CPGs more than once a month but $11 \%$ report never using them. All members of the GPA group report using CPGs in their practice. Pediatricians in the GPB and GPC groups use CPGs less frequently than do GPAs $(\mathrm{p}<0.001)$. There was no significant difference in CPG use related to gender $(\mathrm{p}=0.67)$, years of experience $(\mathrm{p}=0.86)$ or location of practice (Edmonton versus Ottawa) $(\mathrm{p}=0.31)$.

Almost all physicians use both AAP and CPS CPGs (Figure 2). 


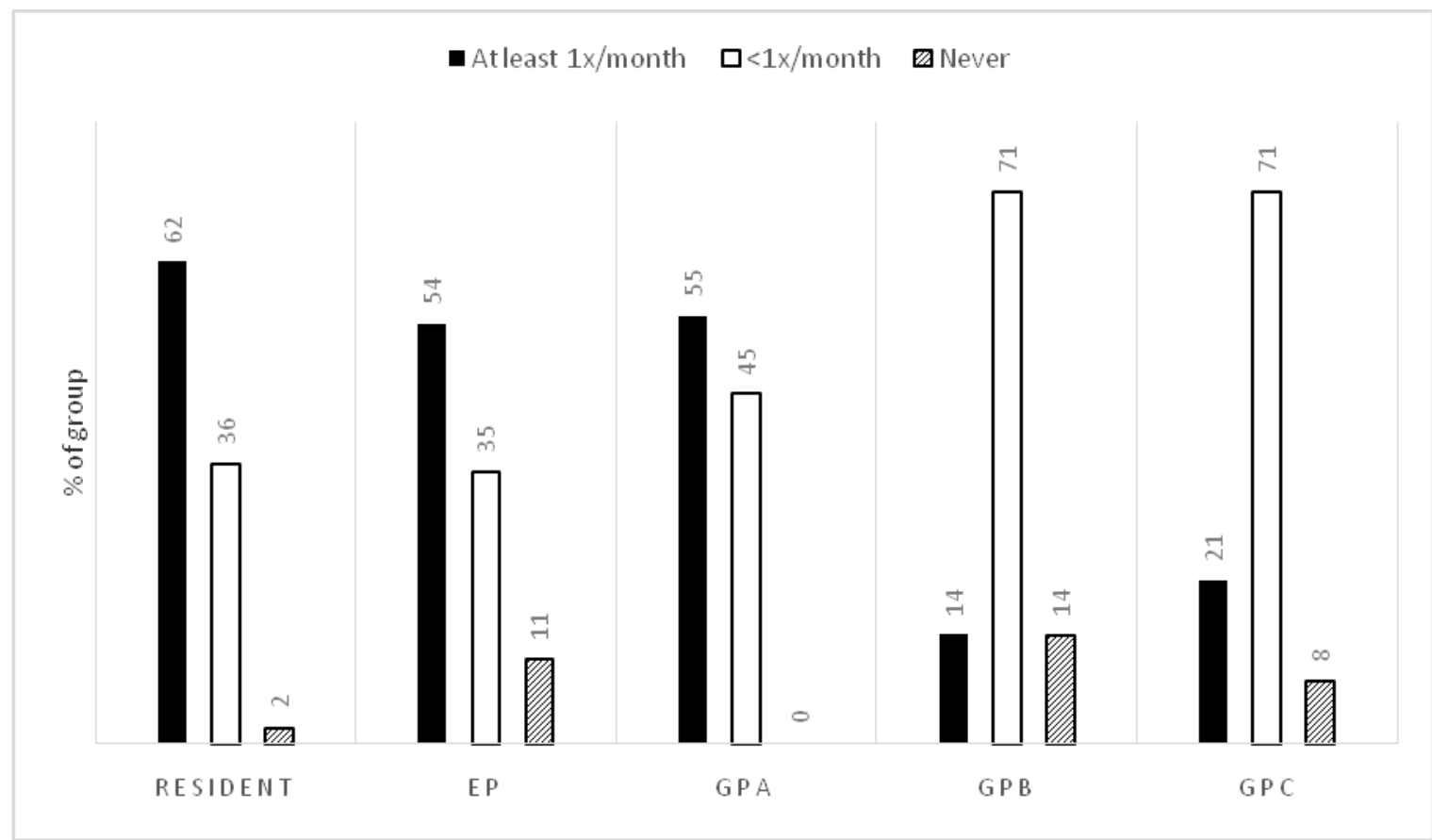

Fig. 1: Frequency at Which Physicians Refer to Clinical Practice Guidelines for Management of Specific Cases.

Legend: EP: Emergency physician; GPA: General pediatricians working >6 weeks/year on a clinical teaching unit (CTU), GPB: General pediatricians working 1-6 weeks/year on CTU, GPC: General pediatricians who rarely or never work on CTU ( $\mathrm{p}=0.0003$ Kruskal Wallis test)

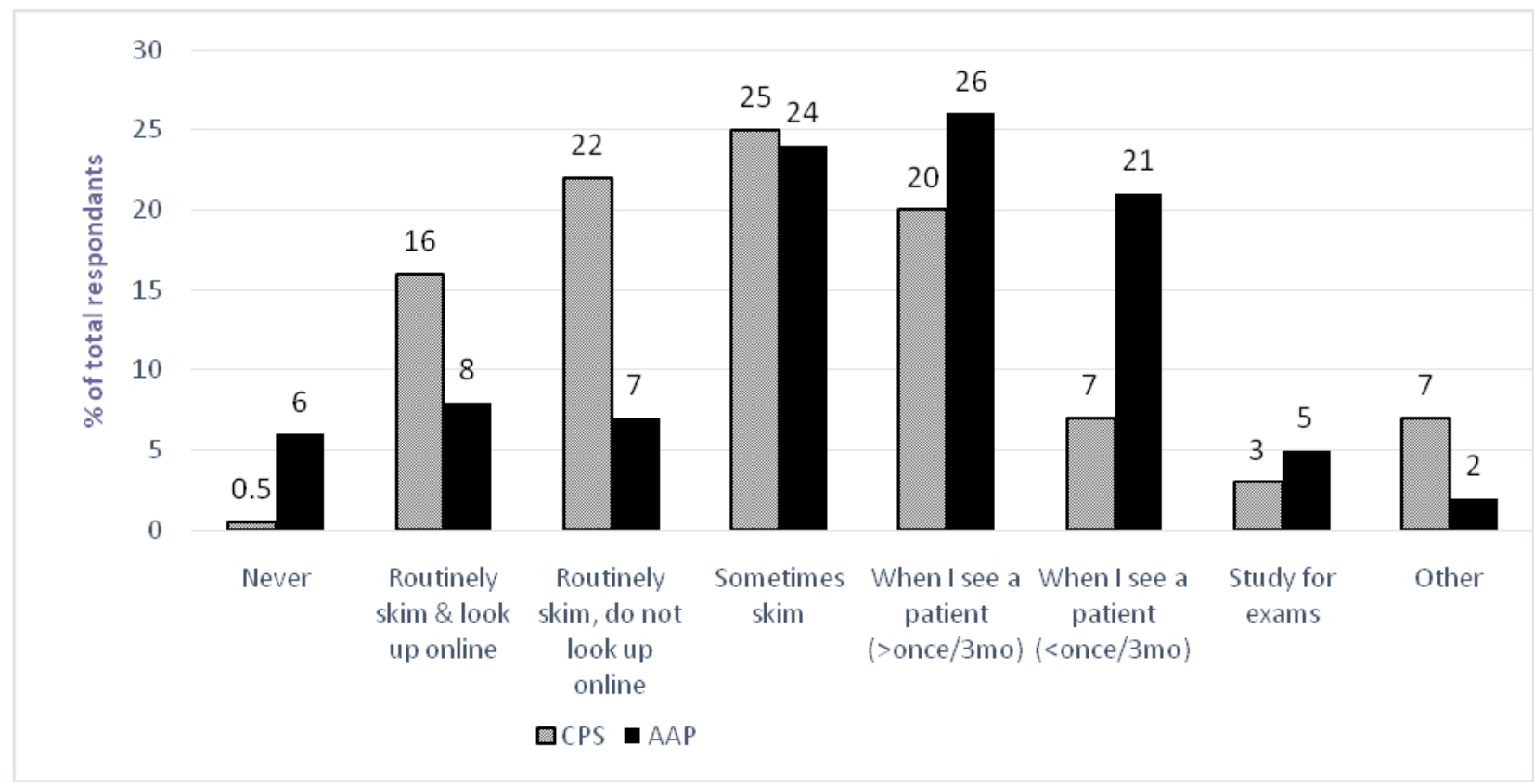

Fig. 2: Overall Trends in Ways that Pediatric Physicians Review Clinical Practice Guidelines (\% of Total Respondents).

Legend: AAP: American Academy of Pediatrics; CPS: Canadian Paediatric Society; EP: Emergency physicians; GPA: General pediatricians working >6 weeks/year on a clinical teaching unit (CTU); GPB: General pediatricians working 1-6 weeks/year on CTU; GPC: General pediatricians who rarely or never work on CTU.

Respondents are more likely to routinely read CPS CPGs when they are published rather than referring to them for advice about a specific case $(p<0.001)$ while the opposite appears to be true for AAP guidelines.

\subsection{Level of agreement with CPGs}

Respondents were more likely to use $(\mathrm{p}<0.001)$ and agree with ( $\mathrm{p}<0.001$ ) CPGs published by CPS, compared with AAP. Overall, $89 \%$ of respondents agreed that using CPGs allowed them to pro- vide better patient care, while $12 \%$ of respondents reported at least once following a CPG they disagreed with due to fear of being blamed or sued.

\subsection{Barriers to CPG use}

There were no significant differences in barriers identified by frequent users (residents, EP and GPA) versus less frequent users (GPB and GPC). Forgetting that a CPG exists or lack of a CPG on 
their question appeared to be the most common barriers in the list of options provided (Table 2).

\subsection{Suggestions for CPG topics and format}

The most common topics that respondents would like to see covered in future CPS guidelines include urinary tract infections, asthma, bronchiolitis, gastroesophageal reflux disease, mental health issues, seizures, headache and acute life threatening events (ALTEs). Many respondents commented they would like to have up-to-date Canadian guidelines for topics for which there are AAP CPGs including circumcision, urinary tract infections and health supervision for chronic medical conditions. There were also requests for CPS CPGs on topics that already exist including international adoption, and return-to- play post-concussion.

One recommendation was that the CPS and AAP consistently disclose the grade of evidence behind recommendations. There were comments on the need for flexibility in practice and the value of clinical experience in managing patients. Others supported guideline use as both a clinical resource and a teaching tool, especially in emerging areas of pediatrics where physicians may not have received extensive training.

All groups are more likely to access CPGs electronically using desktop computers or handheld devices rather than reading paper copies. Respondents currently access CPGs with a desktop computer $(69 \%)$, with a handheld device $(22 \%)$, via a saved electronic copy $(15 \%)$ and via a saved paper copy $(7 \%)$ with some providing more than one answer. When asked about various methods to improve accessibility of CPGs, there was overwhelming support for smartphone applications, online summaries of the CPGs, email notifications and continuing medical education (CME) credits for reading CPGs (Table 3). Respondents did not currently favour Facebook or Twitter notifications.

Table 2: Barriers to CPG Use as Reported By Residents, Emergency Physicians and General Pediatricians. Total Number of Respondents (\% of Group).

\begin{tabular}{|c|c|c|c|c|c|c|c|}
\hline & & $\begin{array}{l}\text { RES } \\
(\mathrm{N}=80)\end{array}$ & $\begin{array}{l}\mathrm{EP} \\
(\mathrm{N}=38)\end{array}$ & $\begin{array}{l}\text { GPA } \\
(\mathrm{N}=11)\end{array}$ & $\begin{array}{l}\text { GPB } \\
(N=14)\end{array}$ & $\begin{array}{l}\text { GPC } \\
(\mathrm{N}=24)\end{array}$ & $\begin{array}{l}\text { TOTAL } \\
(\mathrm{N}=167)\end{array}$ \\
\hline \multirow{3}{*}{$\begin{array}{l}\text { Trouble finding a CPG when } \\
\text { I need it. }\end{array}$} & Often & $5(6)$ & $3(8)$ & $1(9)$ & $0(0)$ & $6(25)$ & $15(9)$ \\
\hline & Sometimes & $55(69)$ & $17(45)$ & $5(45)$ & $9(64)$ & $14(58)$ & $100(60)$ \\
\hline & Never & $20(25)$ & $18(47)$ & $5(45)$ & $5(36)$ & $4(17)$ & $52(31)$ \\
\hline \multirow{3}{*}{$\begin{array}{l}\text { Forget that CPGs exist for a } \\
\text { problem I am seeing }\end{array}$} & Often & $22(28)$ & $5(13)$ & $2(18)$ & $3(21)$ & $5(22)$ & $37(22)$ \\
\hline & Sometimes & $50(63)$ & $30(79)$ & $8(73)$ & $10(71)$ & $16(70)$ & $114(69)$ \\
\hline & Never & $8(10)$ & $3(8)$ & $1(9)$ & $1(7)$ & $2(9)$ & $15(9)$ \\
\hline \multirow{2}{*}{$\begin{array}{l}\text { Do not have time to look up } \\
\text { CPGs when I need them }\end{array}$} & Often & $12(15)$ & $8(21)$ & $1(9)$ & $4(29)$ & $5(22)$ & $30(18)$ \\
\hline & Never & $10(13)$ & $9(24)$ & $3(27)$ & $2(14)$ & $2(9)$ & $26(16)$ \\
\hline \multirow{4}{*}{ Do not think of using CPGs } & Often & $4(5)$ & $6(16)$ & $1(9)$ & $3(21)$ & $4(17)$ & $18(11)$ \\
\hline & Sometimes & $50(63)$ & $19(50)$ & $8(73)$ & $8(57)$ & $12(52)$ & $97(58)$ \\
\hline & Never & $26(33)$ & $13(34)$ & $2(18)$ & $3(21)$ & $7(30)$ & $51(31)$ \\
\hline & Often & $7(9)$ & $9(24)$ & $1(9)$ & $5(36)$ & $5(22)$ & $27(16)$ \\
\hline \multirow[t]{2}{*}{ Find CPGs too long } & Sometimes & $63(79)$ & $22(58)$ & $8(73)$ & $7(50)$ & $14(61)$ & $114(69)$ \\
\hline & Never & $10(13)$ & $7(18)$ & $2(18)$ & $2(14)$ & $4(17)$ & $25(15)$ \\
\hline \multirow{2}{*}{$\begin{array}{l}\text { No CPG on my question, } \\
\text { even though I think there } \\
\text { should be }\end{array}$} & Often & $13(16)$ & $5(13)$ & $2(18)$ & $1(7)$ & $2(9)$ & $23(14)$ \\
\hline & Never & $9(11)$ & $2(5)$ & $0(0)$ & $5(31)$ & $3(13)$ & $19(11)$ \\
\hline \multirow{3}{*}{$\begin{array}{l}\text { Even though there is a CPG, } \\
\text { it does not answer my ques- } \\
\text { tion clearly }\end{array}$} & Often & $6(8)$ & $4(11)$ & $2(18)$ & $2(14)$ & $2(9)$ & $16(10)$ \\
\hline & Sometimes & $59(74)$ & $30(79)$ & $8(73)$ & $10(71)$ & $16(70)$ & $123(74)$ \\
\hline & Never & $15(19)$ & $4(11)$ & $1(9)$ & $2(14)$ & $5(22)$ & $27(16)$ \\
\hline \multirow{3}{*}{$\begin{array}{l}\text { Recommendations are not } \\
\text { clear }\end{array}$} & Often & $4(5)$ & $2(5)$ & $1(9)$ & $1(7)$ & $2(9)$ & $10(6)$ \\
\hline & Sometimes & $47(59)$ & $27(71)$ & $9(82)$ & $9(64)$ & $14(61)$ & $106(64)$ \\
\hline & Never & $29(36)$ & $9(24)$ & 1(9) & $4(29)$ & $7(30)$ & $50(30)$ \\
\hline \multirow{3}{*}{$\begin{array}{l}\text { Disagree with recommenda- } \\
\text { tions }\end{array}$} & Often & $0(0)$ & $2(5)$ & $1(9)$ & $0(0)$ & $0(0)$ & $3(2)$ \\
\hline & Sometimes & $33(41)$ & $26(68)$ & $7(64)$ & $9(64)$ & $16(70)$ & $91(55)$ \\
\hline & Never & $47(59)$ & $10(26)$ & $3(27)$ & $5(36)$ & $7(30)$ & $72(43)$ \\
\hline
\end{tabular}

Legend: CPG: clinical practice guideline; EP: Emergency physicians; GPA: General pediatricians who work >6weeks/year on a clinical teaching unit (CTU); GPB: General pediatricians who work 1-6 weeks/year on CTU; GPC: General pediatricians who rarely or never work on CTU; RES: residents.

Table 3: Median Percentage Chance that Pediatric Physicians Would Use Guidelines in these Formats If they were provided by CPS or AAP

\begin{tabular}{|c|c|c|c|c|c|c|}
\hline & & $\operatorname{RES}(\mathrm{n}=80)$ & $\begin{array}{l}\mathrm{EP} \\
(\mathrm{n}=38)\end{array}$ & GPA $(n=11)$ & $\begin{array}{l}\text { GPB } \\
(n=14)\end{array}$ & $\begin{array}{l}\text { GPC } \\
(n=23)\end{array}$ \\
\hline \multirow{2}{*}{ Smartphone application } & CPS & 95 & 80 & 75 & 83 & 50 \\
\hline & AAP & 90 & 72 & 73 & 78 & 24 \\
\hline Email notifications & AAP & 75 & 69 & 85 & 73 & 71 \\
\hline \multirow{2}{*}{ Facebook notifications } & CPS & 17 & 0 & 0 & 1 & 2 \\
\hline & AAP & 11 & 0 & 0 & 0 & 2 \\
\hline \multirow{2}{*}{ Twitter notifications } & CPS & 1 & 0 & 2 & 0 & 1 \\
\hline & AAP & 0 & 0 & 0 & 0 & 1 \\
\hline \multirow{2}{*}{ Online summaries } & CPS & 83 & 77 & 98 & 78 & 77 \\
\hline & AAP & 79 & 77 & 80 & 78 & 78 \\
\hline \multirow{2}{*}{ Print summaries } & CPS & 52 & 51 & 76 & 63 & 70 \\
\hline & AAP & 52 & 50 & 71 & 66 & 75 \\
\hline \multirow{2}{*}{ CME credits for reading CPGs } & CPS & 72 & 73 & 77 & 80 & 67 \\
\hline & AAP & 61 & 67 & 80 & 76 & 59 \\
\hline
\end{tabular}

Legend: AAP: American Academy of Pediatrics; CME: Continuing Medical Education. CPG: clinical practice guideline; CPS: Canadian Paediatric Society; EP: Emergency physicians, GPA: General pediatricians who work >6weeks/year on a clinical teaching unit (CTU), GPB: General pediatricians who work 1-6 weeks/year on CTU, GPC: General pediatricians who rarely or never work on CTU. RES: Residents. 


\section{Discussion}

There appear to have been marked changes in the use of CPGs by pediatric physicians since the 2000 AAP survey (Flores et al. 2000). The vast majority of respondents use CPGs in their practice. Residents, EPs and pediatricians working frequently on clinical teaching units (GPA) report the most frequent use than do pediatricians who do minimal teaching on inpatients $(p<0.001)$. This suggests that one of the primary uses of CPGs may be for teaching and learning rather than for clinical advice about a specific case. The busy pace of pediatric emergency rooms and CTUs may favor the frequent use of CPGs for their benefits in improving efficiency and standardizing care between providers, while general pediatricians with primarily office practices may have a greater degree of flexibility in developing personalized management plans.

In looking at the patterns of using CPGs, it appears that of the respondents, the frequent users (residents, EP, and GPA) more routinely skim or read new CPS guidelines when they come out, but the resident and GPA groups more often familiarize themselves with AAP CPGs only when they need advice for a specific case. This may be related to a perceived expectation that Canadian physicians comply with CPS CPGs. Also, although the AAP had only 21 CPGs as of October 2014, they have hundreds of policy statements so physicians no doubt, find it easier to keep up with CPS Position Statements and Practice Points, with typically one or two new ones coming out monthly.

A large number of physicians frequently forget that a CPG exists for a given problem while many others have trouble finding a CPG when they need it, suggesting that the CPS and AAP could improve uptake by promoting CPGs or reorganizing their websites so that clinicians can quickly find relevant CPGs. This problem could be overcome if electronic medical records provided links to CPGs based upon the diagnoses selected. Almost all respondents thought that CPGs were sometimes or often too long, but are difficult to balance this with the fact that a similar percentage thought that CPGs often or sometimes do not answer their question. The fact that physicians seem to refer to UpToDate more than to CPGs despite the fact that many have to pay to access UpToDate may stem from the fact that they find answers to clinical questions faster or more reliably on UpToDate, or that they trust that it will truly be up-to-date.

Over half of respondents reported at least sometimes disagreeing with published CPGs and the majority of physicians have sometimes found recommendations to be unclear. This survey did not address which recommendations physicians disagreed with and whether they disagree with recommendations of CPGs in general or how they apply to particular patients. However, previous studies have found that physicians oppose using CPGs rigidly, preferring the flexibility to adapt management strategies to individual patients (Flores et al. 2000).

Only $7 \%$ of respondents use paper copies of CPGs, suggesting that resources need to be focussed on improving electronic accessibility to CPGs. Physicians are keen on smartphone applications, email reminders of updates, online summaries, and receiving continuing medical education credit for reading CPGs. The AAP has developed a smartphone application, but it is not specific to their CPGs.

Although the response rate for the survey was a respectable $42 \%$ for pediatricians, it was low for residents (14\%) and may not be a representative sample. The low response rate may be due to the fact that the survey was done in June when residents were finishing their academic year. Residents from across the country were surveyed but pediatricians were sampled from only one western and one central Canadian city, potentially affecting the generalizability of results. Future studies should also include family physicians, as they provide a substantial amount of primary pediatric care. The term "CPG" could be ambiguous to some respondents; a true CPG contains specific recommendations but some respondents might have been thinking of other AAP and CPS documents, thus affecting their responses. Perhaps some respondents refer to CPGs infrequently as they have memorized the recommendations. The questions about level of agreement with CPGs would be less ambiguous if physicians were asked about specific recommendations rather than CPGs in general as it is common to disagree with at least one recommendation in any CPG, yet to still find it helpful for practice. There may be other common barriers to use of CPGs that the questionnaire did not list. Like all surveys, the answers provided by respondents could be subject to reporting bias, as we depended on physicians' self-report. Ideally, one would analyze adherence to specific recommendations in the CPGs which has been shown to be poor in previous studies (Meehan et al. 2010)

\section{Conclusion}

General pediatricians teaching less than 6 weeks per year on CTUs use CPGs infrequently so are an important target group. However, many of the problems seen in office practice such as behaviour problems and developmental concerns do not lend themselves as well to CPGs as do the typical problems seen in an emergency department. Both residents and pediatricians prefer to access CPGs electronically and would support the development of smart phone applications, email notifications, brief online summaries and provision of continuing medical education credits for reading guidelines. A study on the use of pediatric CPGs amongst family practitioners who regularly care for children would be valuable.

\section{Disclosure}

The funding source for this work was the Women and Children's Health Research Institute (WCHRI). This funding source provided review of the original protocol and funded the statistician but played no other role in data analysis or review of the manuscript. The authors have no conflicts of interest relevant to this article to disclose.

\section{Acknowledgements}

The authors would like to thank Pam Marples and Rick Watts for significant assistance with REDCap and to The Canadian Paediatric Program Directors for helping with distribution of the survey to residents across Canada. Funding was obtained from the Women and Children's Health Research Institute.

\section{References}

[1] Flores G, Lee M, Bauchner H, Kastner B (2000) Physicians' attitudes, beliefs and practices regarding clinical practice guidelines: A national $\begin{array}{llll}\text { survey. } & \text { Pediatrics } & \text { 496-501. }\end{array}$ http://dx.doi.org/10.1542/peds.105.3.496.

[2] Han Y, Carcillo J, Dragotta M, Bills DM, Watson RS, Westerman ME, Orr RA (2003) Early reversal of pediatric-neonatal septic shock by community physicians is associated with improved outcome. Pediatrics 112, 793-799. http://dx.doi.org/10.1542/peds.112.4.793.

[3] Newman R, Hedican E, Herigon J Williams DD, Williams AR, Newland JG (2012) Impact of a guideline on management of children hospitalized with community-acquired pneumonia. Pediatrics 129 , e597e604. http://dx.doi.org/10.1542/peds.2011-1533.

[4] Crabtree E, Mariscalco M, Hesselgrave J Iniguez SF, Hilliard TJ, Katkin JP, McCarthy K, Velasquez MP, Airewele G, Hockenberry MJ (2011) Improving care for children with sickle cell disease/acute chest syndrome. $\quad$ Pediatrics $127, \quad$ e480-e488. http://dx.doi.org/10.1542/peds.2010-3099.

[5] Cabana M, Flores G (2002) the role of clinical practice guidelines in enhancing quality and reducing racial/ethnic disparities in pediatrics. $\begin{array}{llll}\text { Pediatric Resp } & \text { Review } & \text { 3, } & \end{array}$ http://dx.doi.org/10.1053/prrv.2002.0182. 
[6] Meehan W, Fleegler E, Bachur R (2010) Adherence to guidelines for managing the well-appearing febrile infant. Ped Emerg Care 26, 875 880. http://dx.doi.org/10.1097/PEC.0b013e3181fe90d1.

[7] Burns KE, Duffett M, Kho ME, Meade MO, Adhikari NK, Sinuff T, Cook DJ; ACCADEMY Group (2008) A guide for the design and conduct of self-administered surveys of clinicians. CMAJ 179, 245 252. http://dx.doi.org/10.1503/cmaj.080372.

[8] Harris PA, Taylor R, Thielke R, Payne J, Gonzalez N, Conde JG (2009) Research electronic data capture (REDCap) - a metadatadriven methodology and workflow process for providing translational research informatics. $\mathrm{J}$ Biomed Inform 42, 377-381. http://dx.doi.org/10.1016/j.jbi.2008.08.010.

\section{Appendix}

\section{* Questionnaire}

1) Please select the option that applies the most to you:

- $\quad$ Resident, Please specify - R1,R2,R3,R4

- I teach on a clinical teaching unit ( CTU) as a general pediatrician for more than 6 weeks per year

- I teach on a clinical teaching unit (CTU) as a general pediatrician for an average of 1 to 6 weeks per year

- I work as a general pediatrician but rarely or never teach on CTU anymore

- Emergency Physician

- Other or no longer in practice - Do not let them complete survey

2) Gender

3) How many years have you been in practice? years (residents do not get this question)

4) Do you have an office practice? If yes, how many outpatients do you see on an average full work day? Patients.

5) The following questions are about your opinion about Clinical Practice Guidelines (CPGs)

Which best describes when you currently read the following guidelines, assuming that they are on topics that are relevant to your practice Canadian Paediatric Society guidelines (http://www.cps.ca/en/documents).

- I have never read CPS guidelines.

- I routinely at least skim CPS guidelines as they are published in Pediatrics and Child Health. If only a summary is published there, I usually read the on-line version.

- I routinely at least skim CPS guidelines as they are published. However, if only a summary is there, I do not usually read the guideline on-line

- I sometimes skim or read part of new CPS guidelines as they are published, but I do not do so routinely.

- I read CPS guidelines only when I see a patient that they apply to. On average, this happens at least once every 3 months.

- I read CPS guidelines only when I see a patient that they apply to. On average, this happens less often than once every 3 months

- I memorize (d) CPS guidelines to study for exams but do not currently use them for patient care.

- Other - explain

6) This was identical to question 5 but asked about American Academy of Paediatrics internal and endorsed guidelines (http://pediatrics.aappublications.org/site/aappolicy/index.X html)

7) How often do you refer to a clinical practice guideline for managing specific cases?

- At least once per month

- Sometimes but less than once per month

- Never (skip questions 8,9)

8) How often do you use the following clinical practice guidelines for managing specific cases, assuming there is a guideline on that topic?

- CPS sliding scale Never use them Use them very often

- AAP sliding scale
- other specify which (provide room for more than one other guideline)

9) Which best describes the way you usually find a clinical practice guideline when you need it?

- Look up the paper copy or journal that I have saved.

- Look them up on-line on a desk-top computer.

- Look them up on-line on a hand-held device.

- Look them up in the copy I saved electronically

- Other - describe

10) I usually agree with the recommendations in CPS guidelines

- Sliding scale $0=$ almost never; $100=$ almost always

- I do not know enough about their content to say

11) I usually agree with the recommendations in AAP guidelines

- $\quad$ Sliding scale $0=$ almost never; $100=$ almost always

- I do not know enough about their content to say

12) Clinical Practice Guidelines allow me to provide better patient care.

- Agree

- No opinion.

- Disagree.

13) I have at least once followed a Clinical Practice Guideline that I disagreed with as I worry that I will be blamed or sued if I do not and the patient then have a poor outcome.

- yes

- no

14) How often are the following barriers that you encounter to using clinical practice guidelines (often/sometimes/never) will be put in a table format

- I have trouble finding a guideline when I need it

- I forget that guidelines exist for a problem that I am seeing

- I don't have time to look up guidelines when I need them

- I do not think of using guidelines

- I find guidelines to be too long

- There is no guideline on my question, even though I think that there should be one

- Even though there is a guideline, it does not answer my question clearly

- Recommendations are not clear in the guidelines

- I disagree with the recommendations found in clinical practice guidelines

15) How often do you use the following for clinical advice?

- CPS guidelines

- AAP guidelines

- Up-to-Date

- Databases such as Medline/ PubMed

- Textbook

- At least once per week

- Sometimes but less than once per week

- Never

16) What is the percentage chance that you would use each of the following if the CPS provided them (sliding scale 0 to $100 \%)$ ? Answer $100 \%$ if it already exists and you currently use it.

- Smart phone app with all guidelines

- Email notifications of new guidelines or updates

- Facebook notifications of new guidelines

- Twitter notifications of new guidelines

- One or two page summaries of each guideline on-line

- One or two page summaries of each guideline in a print format

- CME credits for doing a quiz on new or updated guidelines

17) What is the percentage chance that you would use each of the following if the AAP provided them (sliding scale -0 to $100 \%$ ) Answer $100 \%$ if it already exists and you currently use it.

- Smart phone app with all guidelines 
- Email notifications of new guidelines or updates

- Facebook notifications of new guidelines

- Twitter notifications of new guidelines

- One or two page summaries of each guideline on-line

- One or two page summaries of each guideline in a print format

- CME credits for doing a quiz on new or updated guidelines

18) List specific topics that you would like to see covered in CPS guidelines.

19) List specific topics that you would like to see covered in AAP guidelines.

20) Any other comments? Blank space 